\title{
Anticorpos antialfavírus detectados em equinos durante diferentes epizootias de encefalite equina, Paraíba, 2009
}

\section{Antibodies to alphavirus detected in horses during different epizootics of equine encephalitis, Paraiba state, Brazil, 2009}

\author{
Francisco Anilton Alves Araújo, ${ }^{*, * *}$ Maria Auxiliadora Andrade, ${ }^{* *}$ Valéria Sá Jayme, ${ }^{* *}$ Arthur Levantezi Santos, ${ }^{*}$ \\ Alessandro Pecego Martins Romano, ${ }^{*, * *}$ Daniel Garkauskas Ramos, ${ }^{*}$ Elenice Maria Sequetin Cunha, ${ }^{* * *}$ \\ Milene Silveira Ferreira, ${ }^{* *}$ Maria do Carmo Custódio Souza Hunold Lara, ${ }^{* * *}$ Eliana Monteforte Cassaro Villalobos, ${ }^{* * *}$ \\ Lívia Caricio Martins*
}

\begin{abstract}
Resumo
Algumas doenças neuroinvasivas em equinos têm um caráter antropozoonótico, e seu diagnóstico é hoje um dos grandes problemas encontrados pelas autoridades públicas para que se possa implementar uma política de prevenção, vigilância e controle no Brasil. Os objetivos deste estudo foram determinar a prevalência de anticorpos inibidores da hemaglutinação para alfavírus em amostras de soro de 182 equinos investigados durante diferentes epizootias ocorridas na Paraíba, em 2009, bem como comparar os resultados obtidos no teste de inibição por hemaglutinação para o vírus da Encefalite Equina do Leste (EEL) com os de soroneutralização em microplacas para este mesmo vírus. Foi realizada coleta de sangue em 182 equídeos, distribuídos em 15 municípios da região oeste da Paraíba, onde existia relato da doença e/ou morte de equinos. Observou-se uma prevalência clínica para Encefalite Equina do Leste de $12,8 \%$, prevalência real (PRNT) de $63,7 \%$ e prevalência aparente $(\mathrm{IH})$ de $54,3 \%$. Quando comparados os resultados obtidos no teste de inibição de hemaglutinação com os de soroneutralização, observou-se uma sensibilidade de $77,6 \%$ e especificidade de $86,4 \%$ no primeiro teste. Os valores preditivos positivos e negativos foram de $90,9 \%$ e $68,7 \%$, respectivamente. O estudo revelou um grande número de animais sorologicamente reagentes e sem manifestação clínica aparente. Os resultados do teste de inibição de hemaglutinação associados às informações clínicas, epidemiológicas e ao diagnóstico virológico (detecção de genoma viral) foram capazes de confirmar as epizootias na área e demonstram que esta técnica pode ser recomendada como de triagem em inquéritos sorológicos desta natureza pelas elevadas sensibilidade e especificidade do teste.
\end{abstract}

Palavras-chave: epizootia encefalitogênica, soroneutralização.

\begin{abstract}
Neuroinvasive diseases diagnosis in horses is a major issue in defining surveillance policies in Brazil. In order to determine the prevalence of hemagglutination inhibition antibodies to alphaviruses and compare the results obtained from this technique for EEE virus to those obtained from plaque reduction neutralization test, blood sample was taken from 182 horses during the investigation of epizootics occurred in 15 municipalities of Paraiba state, in 2009, where there were reports of death or illness in horses. The clinical prevalence for EEE virus, assessed from sick animals, was 12.8\%, while the real (PRNT) and the apparent (IH) prevalences were $63.7 \%$ and $54.3 \%$, respectively. Compared to the PRNT, the IH test has shown a sensibility of $77.6 \%$ and a specificity of $86.4 \%$. The positive and negative predictive values were $90.9 \%$ and $68.7 \%$. A high number of serologically reactive animals without apparent symptoms were revealed. These results, associated to clinical and epidemiological data and to virological diagnosis (PCR), were able to confirm the epizootics in the area for EEE, and demonstrate that the $\mathrm{IH}$ test can be used for screening in serological surveys because of its high sensibility and specificity.
\end{abstract}

Keywords: epizootic, encephalitogenic, seroneutralization.

\section{Introdução}

A família Togaviridae é composta por dois gêneros: Alphavirus e Rubivirus. O gênero Alphavirus é de interesse para a arbovirologia e abrange aproximadamente 30 espécies, algumas das quais têm sido associadas com doenças em animais domésticos (equídeos e aves), silvestres (aves e mamíferos) e ocasionalmente em humanos. Os alfavírus possuem características estruturais e morfológicas em comum, com considerável relação antigênica, e são transmitidos por artrópodes, principalmente mosquitos culicídeos (Flores, 2007).

\footnotetext{
* Secretaria de Vigilância em Saúde - Ministério da Saúde - SCS-Quadra 4 - BI.A - 2º Andar - Ed Principal/ CEP 70.304.000 - Brasília/DF. Autor para correspondência: E-mail: faaraujo1@gmail.com

*** Programa de Pós-Graduação em Ciência Animal (Doutorado) - Escola de Veterinária e Agronomia - Universidade Federal do Goiás. Campus II Samambaia, Cx. Postal 131, CEP 74001-970 - Goiânia - Goiás -Brasil

*** Instituto Biológico de São Paulo. Avenida Conselheiro Rodrigues Alves, 1.252 - CEP 04014- 002. São Paulo/SP
} 
Devido ao potencial de causar doença neurológica, os vírus da Encefalite Equina do Oeste (WEEV), da Encefalite Equina do Leste (EEEV) e o da Encefalite Equina Venezuelana (VEEV) são os alfavírus de maior interesse no estudo das arboviroses no Brasil (Vasconcelos et al., 1991). Dentre estes, o EEEV é o que apresenta maior virulência e patogenicidade (Arrigo et al., 2010). O EEEV tem algumas espécies de mosquitos dos gêneros Culex, Aedes, Anopheles e Culiseta como vetores potenciais, equídeos e humanos como hospedeiros acidentais, e como principais reservatórios, as aves silvestres (Figueiredo, 2007).

Esse vírus tem sido isolado e anticorpos detectados em vários países das Américas, desde o Canadá até a Argentina (Lopes e Saccheta, 1974; Monath et al., 1985; Kotait et al., 1992; Iversson et al., 1993; Vasconcelos et al., 1998; Silva et al., 1999; Heinemann et al., 2006; Cunha et al., 2009; Casseb, 2010 e Pauvolid-Corrêa et al., 2011). No Brasil, dentre os vírus causadores de encefalite em equinos o EEEV é o único que tem sido esporadicamente isolado de animais com sintomatologia nervosa (Nilsson e Sugay, 1962; Kotait et al., 1992; Figueiredo, 2007).

Estudos realizados no Brasil demonstram a presença de anticorpos ou isolamento viral em equídeos dos EEEV, WEEV, VEEV e WNV. Entretanto, somente no caso do VEEV eles atuam como amplificadores do vírus (Kotait et al., 1992; Figueiredo, 2007; Cunha et al., 2009; Casseb, 2010 e Pauvolid-Corrêa et al., 2011 ). Brault et al. (1999) e Arrigo et al. (2010), em estudos realizados sobre o EEEV demonstram a existência de quatro linhagens genéticas distintas deste vírus, diferentes em sua patogenicidade, distribuição geográfica e perfil epidemiológico.

O método de diagnóstico mais empregado na investigação de eventos epidêmicos é a pesquisa de anticorpos mediante técnica sorológica, como inibição de hemaglutinação $(\mathrm{IH})$, teste de neutralização por redução de placas (PRNT), teste de soroneutralização em microplacas (SN) ou teste imunoenzimático (ELISA) (Cunha et al., 2009).

Os objetivos deste estudo foram determinar a prevalência de anticorpos inibidores da hemaglutinação para alfavírus em equinos durante diferentes epizootias ocorridas na Paraíba, entre maio e junho de 2009, e avaliar o desempenho do teste de inibição da hemaglutinação para detecção de anticorpos antiEEEV em relação ao teste de soroneutralização em microplacas.

\section{Materiais e métodos}

Em julho de 2009, foi realizado um estudo transversal, utilizandose as amostras de sangue de $100 \%$ da população de equinos de 57 fazendas com ocorrência de epizootias causadas pelo EEEV, confirmadas por meio de RT-PCR ou com relatos de doença ou morte de animais com sintomas compatíveis com Encefalites Equinas, sem histórico anterior de surtos dessa natureza na área. O material foi coletado em 15 municípios da região oeste da Paraíba (Belém do Brejo do Cruz, Brejo do Cruz, Cajazeirinhas, Condado, Coremas, Patos, Paulista, Piancó, Poço José de Moura, São Bentinho, São Bento, São Francisco, São João do Rio do Peixe, São José do Brejo do Cruz, Vista Serrana).

Os animais foram identificados por meio de ficha individual, contendo: município, nome do proprietário, nome e/ou número do animal, local de realização do inquérito, espécie (equino, asinino, muar), idade (< de 1 ano, de 1 a $\leq 5$ anos, $>5$ anos e $\mathrm{NI}$ (não informado), sexo, utilidade (trabalho, esporte, passeio, reprodução, outra e não informado), histórico vacinal contra EE e resultados laboratoriais.

Para evitar interferência de uma possível imunidade materna, foi coletado sangue de somente 13 animais com idade $<6$ meses e observada a demonstração de títulos de anticorpos nesses animais. Para efeito do estudo, foi considerado animal positivo aquele reagente ao teste de soroneutralização em microplacas (padrão-ouro). Durante a coleta de sangue, os animais com clínica neurológica compatível com EE foram classificados como doentes, considerando-se o vínculo epidemiológico com a detecção de genoma viral em amostras de cérebro de equinos da área, além da interação temporal e espacial e o resultado sorológico positivo para EE no teste padrão-ouro dos animais considerados doentes,

As amostras de sangue foram coletadas da veia jugular, centrifugadas, conservadas em duplicata em nitrogênio líquido $e$ encaminhadas para o Instituto Evandro Chagas, em Belém/PA, e para o Instituto Biológico, em São Paulo/SP, para a realização dos testes de $\mathrm{IH}$ e SN, respectivamente.

$\mathrm{O}$ teste de $\mathrm{IH}$ foi realizado de acordo com a metodologia descrita por Clark \& Casals (1958) e adaptado para microplacas conforme descrito por Shope (1963). Os soros foram testados para detecção de anticorpos inibidores da hemaglutinação em um painel contendo os seguintes alfavírus: vírus da Encefalite Equina do Leste (EEEV), vírus da Encefalite Equina do Oeste (WEEV), vírus Mayaro (MAYV) e o vírus Mucambo (MUCV), que é uma variante do vírus da Encefalite Equina Venezuelana VEEV. Foi considerado como ponto de corte (cutoff) a diluição de 1:20, conforme padronizado pelo Instituto Evandro Chagas, laboratório de referência nacional para arboviroses. As respostas de anticorpos antialfavírus detectados nos equinos foram classificadas em reação monotípica (RM), representadas por aquelas amostras com título de anticorpos $\geq 1: 20$ para apenas um alfavírus, e reação cruzada ( $R C)$, referente às amostras com título de anticorpos $\geq 1: 20$ para mais de um alfavírus (Rodrigues et al., 2010).

No teste de $\mathrm{SN}$, os soros foram examinados contra o EEEV segundo técnica descrita por Cunha et al., 2009 e foram considerados reagentes os soros com título de anticorpos a partir de 1:10. As amostras reagentes para o EEEV foram testadas ainda para o WEEV, objetivando a busca de possíveis reações cruzadas e os três animais reagentes ao teste para o WEEV foram descartados das análises.

O histórico vacinal dos animais contra as EE foi observado no momento da coleta onde foi confirmado que todos os animais que tinham histórico de vacinação contra as $\mathrm{EE}$, haviam sido vacinados até sete dias antes da coleta de soro, e tinham recebido somente uma dose de vacina. Estes animais foram considerados "não vacinados", tendo em vista não possuírem ainda memória imunológica, pois o antígeno vacinal demora em média 7 a 10 dias para ser modificado e preparado pelas células apresentadoras de antígenos para que sejam reconhecidas pelos linfócitos (Flores, 2007).

Para o cálculo da prevalência clínica, foram considerados os animais doentes com sinais clínicos compatíveis com EEE no momento do estudo. Para o cálculo da prevalência aparente, foram considerados os animais reagentes ao teste de IH (triagem), e para o cálculo da prevalência real, foram considerados os animais reagentes ao teste de SN (Cunha et al., 2009). 
Para análise dos resultados observados no IH em comparação ao SN, foi utilizada uma tabela de contingência (2x2), a partir da qual foram determinados a sensibilidade, a especificidade, os valores preditivos positivo e negativo, e os Likelihood ratios positivo e negativo (Sergeant, 2009).

Os dados obtidos foram confrontados pelo teste do Qui-quadrado $\left(\mathrm{X}^{2}\right)$ admitindo-se nível de significância $(\alpha)$ de $5 \%$ para rejeição da hipótese de nulidade $(p \leq \alpha)$. Para análise de concordância entre os testes diagnósticos, foi utilizado o índice kappa, interpretado de acordo com Landis e Koch (1977). As análises estatísticas foram realizadas utilizando-se o software EpiTools (Sergeant, 2009).

\section{Resultados e discussão}

Dos 182 animais testados, 22 apresentavam clínica compatível com EE na ocasião da coleta de sangue, o que determinou uma prevalência clínica de 12,8\%. Do total, 116 animais foram positivos para o EEEV pelo teste de SN, demonstrando uma prevalência real de $63,7 \%$, e 99 foram positivos pelo teste de $\mathrm{IH}$, com uma prevalência aparente de $54,3 \%$ As altas prevalências de anticorpos observadas demonstram a capacidade do EEEV de causar epizootias de elevada magnitude, tanto pelo número de casos como pela grande área de abrangência, com elevado número de animais infectados, porém assintomáticos (Tabela 1).

Tabela 1: Número de amostras positivas e negativas para o EEEV, segundo o tipo de teste, Paraíba, 2009

\begin{tabular}{clccc}
\hline & \multicolumn{4}{c}{ Teste } \\
& & Soroneutralização & \\
\hline \multirow{3}{*}{ Teste } & Positivo & 90 & 9 & 99 \\
\multirow{2}{*}{ Inibição Hemaglutinação } & Negativo & 26 & 57 & 83 \\
& Total & 116 & 66 & 182 \\
\hline
\end{tabular}

Estudo realizado por Santos et al. (2010) na mesma área registrou um surto envolvendo 74 equinos, com duração de 73 dias e letalidade de $48,6 \%$. Os resultados deste estudo corroboram com as informações apresentadas pelos autores acima, demonstrando uma intensa circulação do vírus na área.

Considerando os 22 animais com clínica neurológica compatível com a EEE, 86,3\% (19/22) foram reagentes ao teste de IH e 95,5\% (21/22) ao teste de SN. Estudo realizado por Pereira et al. (1964) em Itaporanga/SP, com animais na fase aguda da doença, agonizantes, convalescentes e contactantes, demonstrou presença de elevadas taxas de anticorpos contra o EEEV nos soros pesquisados, tanto no teste de IH como no teste de SN, corroborando os achados de Romano-Lieber e Iversson (2000), que classificam o teste de neutralização como a técnica sorológica de maior especificidade para pesquisa de anticorpos antiarbovírus.

Do total de animais testados neste estudo para o $\mathrm{IH}, 56,0 \%$ (102/182) foram reagentes para alfavírus, e destes, 97,0\% (99/102) apresentaram anticorpos contra o EEEV, sendo que $38,4 \%$ (38/99) foram classificados como RM para o EEEV e $61,6 \%(61 / 99)$ foram RC para alfavírus. No caso de WEEV,
$57,8 \%$ (59/102) foram reagentes, sendo que 98,3\% (58/59) foram considerados classificados como RC e uma reação foi monotípica (Rodrigues et al., 2010).

No presente trabalho, com relação à positividade para os anticorpos do MUCV e MAYV, a frequência observada foi de $16,7 \%(17 / 102)$ e $10,8 \%(11 / 102)$, respectivamente, sendo que o MUCV apresentou duas RM, sugerindo a circulação deste agente viral na área.

Heinemann et al. (2006), em Uruará/PA e Casseb (2010) no Pará, utilizando as técnicas de soroneutralização e de $\mathrm{IH}$, respectivamente, encontraram prevalências de anticorpos em equinos de $27,3 \%$ e $30,1 \%$ para o EEEV e $6,8 \%$ e $22,8 \%$ para o WEEV, respectivamente. Além disso, Casseb (2010) detectou prevalência de 5,3\% para o MAYV e MUCV. Fernandez et al. (2000), em estudo realizado no Paraná, encontraram 13,6\% de prevalência de anticorpos contra o MUCV, enquanto não foi detectada presença de anticorpos contra o MAYV por PauvolidCorrêa (2008) em Nhecolândia/MS, sugerindo a ausência do vírus ou de vetores competentes na área estudada, ou ainda a baixa atratividade destes por sangue de equinos.

Considerando os dados de prevalência de anticorpos para EEEV disponíveis na literatura cujo teste diagnóstico utilizado foi o de SN, Monath et al. (1985), observaram 11,0\% de prevalência de anticorpos neutralizantes em equinos na Argentina. Fernandez et al. (2000), no Paraná, entre 1996 e 1999, encontraram prevalência de 54,5\%. Heinemann et al. (2006) detectaram anticorpos neutralizantes de $27 \%$ em Uruará/PA; e Iversson et al. (1993) e Pauvolid-Corrêa et al. (2010) encontraram anticorpos neutralizantes para o EEEV de 6,7\% e 47,7\%, respectivamente, no Pantanal Mato-grossense. Cunha et al. (2009), em São Paulo, entre 2004 e 2005, detectaram anticorpos para o EEEV em 16\% de suas amostras.

Os resultados deste estudo, juntamente com as prevalências observadas por diversos autores em várias regiões do País, demonstram que a circulação do EEEV não somente difere em cada região e aparentemente está relacionada com a presença do vírus, mas também com as características ecológicas do vetor reservatório e dos hospedeiros. Estes achados enfatizam a importância dos equídeos não vacinados como animais sentinelas para monitorar a circulação destes arbovírus.

No presente estudo, das amostras reagentes para EEEV pelo teste de $\mathrm{IH}, 49,5 \%$ (49/99) apresentaram titulação $\geq 1: 320$, e destas, 16,3\% (8/49) apresentaram titulação $\geq 1: 1280$, considerada elevada se comparada ao cutoff estabelecido (1:20), ou aos títulos observados por Pauvolid-Corrêa et al. (2010), sugerindo que a diferença na titulação pode ter sido devido à ocorrência da epizootia no momento da coleta de soro.

Romano-Lieber e Iversson (2000) destacaram que o teste de IH é reconhecidamente sensível para detecção de anticorpos antiarbovírus, enquanto o teste de SN é altamente específico e é empregado no diagnóstico sorológico como teste confirmatório. Desta forma, quando comparados os resultados obtidos no IH com aqueles obtidos a partir da SN, encontrou-se uma sensibilidade de $77,6 \%$ (90/116) e especificidade de $86,4 \%$ (57/66). Os valores preditivos positivo (VPP) e negativo (VPN) foram de $90,9 \%$ (90/99) e 68,7\% (57/83), respectivamente, o que significa que a maioria dos animais positivos detectados pela $\mathrm{IH}$ foram confirmados pela $\mathrm{SN}$, sugerindo que o teste de $\mathrm{IH}$ foi de grande valor para determinar a presença de anticorpos do EEEV na área estudada. 
Ponderando a probabilidade de infecção em indivíduos com teste positivo e teste negativo, o Likelihood ratio positivo encontrado foi de 5,7 e o Likelihood ratio negativo foi de 0,26, sugerindo que a probabilidade de um animal infectado ter o resultado positivo no teste é 22 vezes maior no animal verdadeiramente infectado do que no não infectado. Os resultados também demonstraram que a probabilidade de um indivíduo testado aleatoriamente ser reagente no teste de $\mathrm{IH}$ foi de $45 \%$, considerando a prevalência clínica de cerca $12,8 \%$, enquanto que a probabilidade de resultar negativo foi de $4 \%$.

Quando analisada a concordância entre os testes, obteve-se o índice de kappa de 0,605 (Landis e Kock, 1977), determinando a existência de uma concordância substancial entre os testes, uma vez que dos 99 animais positivos no teste de $\mathrm{IH}, 90$ foram reagentes também no teste confirmatório, o que sugere que o teste de triagem é importante para determinar a presença da circulação de anticorpos virais.

Observou-se, ainda, que a prevalência de anticorpos neutralizantes (SN) foi maior entre os equinos, com $68,5 \%$ (100/146), seguido dos asininos, com 46,7\% (7/15), e muares, com 42,8\% (9/21). A utilização de burros e mulas como animais de carga na Paraíba é comum e permite inferir a possibilidade de uma maior exposição destes animais aos mosquitos vetores infectados. Este fato corrobora com o encontro de Cunha et al. (2009), em estudo realizado no Vale do Ribeira, em São Paulo, entre 2004 e 2005, que apontaram uma elevada prevalência de anticorpos contra o EEEV em muares, devido a esta espécie animal ser utilizada com frequência na coleta do palmito na zona de mata da região.

Do total de machos que participaram do estudo, 65,2\% (60/92) foram reagentes ao teste de SN contra o EEEV. Dentre as fêmeas, 60,4\% (49/81) foram reagentes ao teste. Não houve associação significativa entre o sexo do animal e a positividade no teste $(p>0,05)$.

Considerando os 168 animais com idade conhecida, observouse um aumento significativo dos animais reagentes ao teste de $\mathrm{SN}$ com o avanço da idade (Tabela 2), com associação significativa entre a idade do animal (<1 ano em relação às demais categorias) e a positividade no teste $(p<0,05)$. Não houve diferença significativa quando se considerou a positividade dentro de cada faixa etária $(p>0,05)$.

Considerando o estado vacinal dos animais, $49,5 \%$ (90/182) foram vacinados contra as EE até sete dias antes da coleta de sangue, com prevalências de anticorpos neutralizantes para EEE de 62,2\% (56/90) nos vacinados e de $62,3 \%$ (54/86) nos não vacinados. Não houve associação entre a vacina e a positividade ao teste $(R R=1$; $R A=0 ; p>0,05)$ e isto se deve ao pouco tempo entre a vacinação e a coleta do sangue.

Ponderando as informações obtidas nas localidades, 47,2\% (86/182) dos equinos estudados não tinham histórico de vacinação contra EE e o restante havia sido vacinado até sete dias antes da coleta de soro, tendo recebido somente uma dose de vacina. Estes animais foram considerados "não vacinados", tendo em vista que não houve tempo hábil para produção de anticorpos vacinais que pudessem interferir nos resultados laboratoriais. A vacina contra EE utilizada na região é recomendada a potros a partir de três meses de idade (três doses com intervalos de duas a quatro semanas entre as aplicações), e os títulos protetores são detectáveis a partir de 21 dias após a administração da última dose (Vencofarma, 2011).

Pauvolid-Corrêa (2008), em inquérito realizado no Pantanal, observou uma prevalência de anticorpos para EEEV de 47,7\% em animais não vacinados e com mais de sete meses de idade no momento da coleta do sangue, menor que a prevalência observada neste estudo (65,4\%; 89/136), quando comparados animais da mesma faixa-etária e mesmo estado vacinal, sugerindo que a idade (tempo de exposição) é um fator de risco.

Avaliando a possibilidade de os animais com idade inferior a um ano serem reagentes ao teste de SN devido à imunidade passiva herdada da mãe ou por terem sido vacinados até sete dias antes da coleta do sangue, pode-se observar que dos 33 animais nesta faixa-etária, $17(51,5 \%)$ haviam sido vacinados, e destes, $47,0 \%$ $(8 / 17)$ foram reagentes ao teste. Percentuais semelhantes foram observados nos não vacinados. Não houve associação entre ser reagente ao teste e uma possível imunidade passiva dos animais $(R R=1 ; R A=0 ; p=1)$, e tampouco entre ser reagente ao teste e ser vacinado $(R R=1 ; R A=0 ; p=1)$, conforme já descrito por Bertone (2000). Isto sugere que os animais não adquiriram imunidade materna ou vacinal, estando suscetíveis aos vírus.

Considerando a utilidade dos animais, o maior percentual de positividade foi observado nos animais de passeio, com $75,0 \%$ $(6 / 8)$, seguidos dos animais utilizados para a prática de esportes, com $68,0 \%(17 / 25)$, e para o trabalho, com $61,5 \%(48 / 78)$ (Tabela 2). Por outro lado, quando se considera a positividade por utilidade entre os animais reagentes, pode-se observar que os animais de trabalho representaram $41,4 \%$ (48/116) do total de animais positivos ao teste de SN, não existindo associação

Tabela 2: Soroprevalência em equinos para o vírus da Encefalite Equina Leste (EEEV) detectada pelo teste de soroneutralização (SN) durante um surto clínico no estado da Paraíba, Brasil

\begin{tabular}{lccc}
\hline & Amostrados & $\begin{array}{c}\text { Número de reagentes } \\
\text { (\% da categoria) }\end{array}$ & $\begin{array}{c}\text { Porcentagem de reagentes } \\
\text { com relação ao total de reagentes }\end{array}$ \\
\hline $\begin{array}{l}\text { Idade } \\
<1 \text { ano }\end{array}$ & 33 & $15(45,5)$ & 12,9 \\
1 a 5 anos & 67 & $48(71,6)$ & 41,4 \\
$>5$ anos & 68 & $45(66,2)$ & 38,8 \\
NI & 14 & $8(57,1)$ & 6,9 \\
Aptidão & & $17(68,0)$ & 14,7 \\
Esporte & 25 & $6(75,0)$ & 5,2 \\
Passeio & 8 & $17(58,6)$ & 14,7 \\
Reprodução & 29 & $48(61,5)$ & 41,4 \\
Trabalho & 78 & $13(54,2)$ & 11,2 \\
Outro & 24 & $15(83,3)$ & 12,9 \\
NI & 18 & $116(63,7)$ & \\
\hline Total & 182 & & \\
\hline
\end{tabular}


entre ser positivo ao teste e a utilidade do animal $(p>0,05)$. A proporção de animais positivos foi maior entre os animais de trabalho, seguido dos animais utilizados na prática do esporte e reprodução, demonstrando haver diferença significativa entre as utilidades dos animais $(p<0,05)$.

Por fim, os resultados observados a partir da comparação entre os testes de IH e SN demonstraram que o primeiro pode ser um teste indicado para detectar se ocorreu a circulação viral, não sendo o recomendado para determinar a magnitude da epizootia e que o teste de SN é de fato o padrão-ouro como sugerido na literatura (Cunha et al., 2009).

Esses achados, em conjunto com o já observado por outros autores, enfatizam a importância das epizootias causadas por doenças neuroinvasivas em equinos, e que sua vigilância deve ser usada como ferramenta preditora da ocorrência de casos de encefalites e/ou meningites virais em humanos, determinando, desta forma, uma nova vigilância para estas enfermidades.

\section{Referências}

ARRIGO, N.C.; ADAMS, A.P.; WEAVER, S.C. Evolutionary Patterns of Eastern Equine Encephalitis Virus in North versus South America Suggest Ecological Differences and Taxonomic Revision. Journal of Virology, Jan. 2010, v. 84, n. 2, p. 1014-1025, 2010. Disponível em: http://jvi.asm.org/cgi/reprint/84/2/1014. Acessado em 22.06.2011.

BERTONE, J.J.. Encefalite causada por Togavírus. In: REED, S. M.; BAYLY, W. M. Medicina Interna Equina. Rio de Janeiro: Guanabara Koogan, 2000. c. 9, p. 432- 436. 2000.

BRAULT, A.C.; POWERS, A.M.; CHAVEZ, C.L.V.; LOPEZ, R.N.; CACHO' N, M.F.; GUTIERREZ, L.F.L.; KANG, W.; TESH, R.B.; SHOPE, R.E.; WEAVER, S.C. Genetic And Antigenic Diversity Among Eastern Equine Encephalitis Viruses From North, Central, And South America. American Journal Tropical Medicine and Hygiene. v. 61, n. 4, p. 579-586, 1999. Disponível em: http://www. ajtmh.org/content/61/4/579.full.pdf+html. Acessado em 21.06.2011. CASSEB, A.R.. Soroprevalência de anticorpos e padronização do teste Elisa Sanduíche Indireto para 19 tipos de arbovírus em herbívoros domésticos. Tese (Doutorado) Universidade Federal do Pará. Instituto de Ciências Biológicas. Belém, 2010.

CDC Technical Fact Sheet: Eastern Equine Encephalitis [editorial]. CDC Division of vector. Borne Infectious Diseases, 2010. Disponível em: http://www.cdc.gov/EasternEquineEncephalitis/tech/ factSheet.html. Acessado em 12.06.2011.

CLARKE, D.H.; CASALS, J. Techniques for hemaglutination and hemagglutination inhibition. With arthropod-borne viruses. American Journal Tropical Medicine and Hygiene, n. 7, p. 561$573,1958$.

CUNHA, E.M.S.; VILLALOBOS, E.M.C.; NASSA, A.F.C.; LARA, M.C.C.S.H.; PERES, N.F.; PALAZZO, J.P.C.; SILVA, A.; DE STEFANO, E.; PINO, F.A. Prevalência de anticorpos contra agentes virais em equídeos no sul do estado de São Paulo. Arquivos do Instituto Biológico de São Paulo, São Paulo, v. 76, n. 2, p.165-171, abr./jun., 2009.

FERNÁNDEZ, Z.; RICHARTZ, R.; TRAVASSOS DA ROSA, A.; SOCCOL, V. T. Identificação do vírus causador de encefalomielite equina, Paraná, Brasil. Revista de Saúde Pública, v. 34, n. 3, p. 232-235, 2000.

FIGUEIREDO, L.T.M. Arboviroses Emergentes no Brasil. Artigo de Opinião. Revista da Sociedade Brasileira de Medicina Tropical. v. 40, n. 2, p. 224-229, março-abril, 2007. Disponível em: http://www. scielo.br/pdf/rsbmt/v40n2/a16v40n2.pdf. Acessado em: 28.08.2011.

\section{Conclusões}

Constatou-se elevada circulação do vírus da Encefalite Equina do Leste entre equinos na área estudada, com elevado número de animais assintomáticos.

O sexo e a idade do animal não demonstraram ser fatores de risco para a exposição ao vírus.

Os resultados obtidos neste estudo sugerem que o teste de Inibição da hemaglutinação pode ser utilizado para triagem em inquéritos sorológicos desta natureza, tendo em vista a substancial concordância observada, além da sensibilidade, especificidade e valores preditivos positivo e negativo, quando comparados com os resultados obtidos no teste de soroneutralização, e não deve ser recomendado para determinar a magnitude da epizootia.

FLORES, E. F.. Classificação e Nomenclatura dos Vírus. Virologia Veterinária. Santa Maria : Ed. da UFSM, 2007, p. 39-58.

HAYES, E.B.; KOMAR, N; NASCI, R.S.; MONTGOMERY, S.P.; O'LEARY, D.R.; CAMPBELL, G.L. Epidemiology and transmission dynamics of West Nile virus disease. Emerging Infectious Diseases. v. 11, p. 1167-1173, 2005.

HEINEMANN, M.B., SOUZA, M.C.C., CORTEZ, A., FERREIRA, F., HOMEM, V.S.F; FERREIRA-NETO, J.S., SOARES, R.M., CUNHA, E.M.S., RICHTZENHAIN, L.J..Soroprevalência da encefalomielite equina do leste e do oeste no Município de Uruará, PA, Brasil. Brazilian Journal of Veterinary Research and Animal Science, v. 43, p. 1-5, 2006.

IVERSSON, L.B.; COIMBRA, T.L.M. Encefalite na região do Vale do Ribeira, São Paulo, Brasil, no período pós-epidêmico de 1978 a 1983. Revista de Saúde Pública, v. 32, p. 323-332, 1984.

IVERSSON, L.B., SILVA, R.A.M.S., TRAVASSOS DA ROSA, A.P.A., BARROS, V.L.R.S. Circulation of Eastern Equine Encephalitis, Wessern Equine Encephalitis, Ilhéus, Maguari and Tacaiuma viruses in equines of the Brazilian pantanal, South America. Revista do Instituto de Medicina Tropical, v. 35, p. 355-359, 1993.

KOTAIT, I.; PEIXOTO, Z. M. P.; COIMBRA, T. L. M.; CUNHA, E. M. S.; QUEIROZ, L. H; MACRUZ, R.; NAGAMORI, A. H. Isolamento e identificação do vírus da encefalomielite equina, tipo leste, em equinos do Estado de São Paulo, Brasil. Arquivos do Instituto Biológico de São Paulo, v. 59, n.1/2, p. 37-41, 1992.

LANDIS, J.R. e KOCH, G.G. The measurement of observer agreement for categorical data. Biometrics, v. 33, n. 1, p. 159-174, 1977.

LOPES, O.S.; SACCHETA, A. Epidemiological studies on eastern equine encephalitis vírus in São Paulo, Brazil. Revista do Instituto de Medicina Tropical, v. 16, n. 5, p. 253-257, 1974.

MONATH, T.P. SABATINI, M.S., PAULI, R., DAFNER, J.F., MITCHEL, C.J. BOWEN, G.S., CROPP, C.B. Arbovirus investigation in Argentina, 1977-1980. American Journal of Tropical Medicine and Hygiene, v. 34; p. 966-975, 1985.

NILSSON, M.R.; SUGAY, W. Ocorrência da encefalomielite equina em Itaporanga, estado de São Paulo. Arquivos do Instituto Biológico de São Paulo, São Paulo, v. 29, p. 63-68, 1962.

PAUVOLID-CORRÊA, A. Estudo sobre arbovírus em populações de equinos e artrópodes na sub-região de Nhecolêndia no Pantanal do mato Grosso do Sul. Dissertação (Mestrado). Instituto Oswaldo Cruz. FIOCRUZ. Rio de Janeiro. p. 180, 2008. 
PAUVOLID-CORREAA, A.; TAVARES, F.N.; COSTA, E.V.; BURLANDY, F.M.; MURTA, M.; PELLEGRIN, A.O.; NOGUEIRA, M.F.; SILVA, E.E.. Serologic evidence of the recent circulation of Saint Louis encephalitis virus and high prevalence of equine encephalitis viruses in horses in the Nhecolândia sub-region in South Pantanal, Central-West Brazil. Memórias do Instituto Oswaldo Cruz, Rio de Janeiro, v. 105, n. 6, p. 829-833, Setembro, 2010.

PAUVOLID-CORREA, A.; MORALES, M.A.; LEVIS, S.; FIGUEIREDO, L.T.M.; COUTO-LIMA, D.; CAMPOS, Z.; NOGUEIRA, M.F.; SILVA, E.E.; NOGUEIRA, R.M.R.; SCHATZMAYR, H.G. Neutralising antibodies for West Nile virus in horses from Brazilian Pantanal. Memórias do Instituto Oswaldo Cruz, Rio de Janeiro, v. 106, n. 4, p. 467-474, June, 2011.

PEREIRA, O.A.; NILSSON, M.R.; SUGAY, W.; TRAPP, E.E. Ocorrência de Encefalomielite Equina em Itaporanga, estado de São Paulo (Brasil). II Estudos Sorológicos. Revista do Instituto de Medicina Tropical de São Paulo. v. 6, p. 1-4. 1964.

RODRIGUES, S.G.; OLIVA, O.P.; ARAÚJO, F.A.A.; MARINS, L.C.; CHIANG, J.O.; HENRIQUES, D.F.; SILVA, E.V.P.; RODRIGUES, D.S.G.; PRAZERES, A.S.C.; TAVARES-NETO, J.; VASCONCELOS, P.F.C. Epidemiology of Saint Louis encephalitis virus in the Brazilian Amazon region and in the State of Mato Grosso do Sul, Brazil: elevated prevalence of antibodies in horses. Revista Panamazônica de Saúde, n.1, p. 81-86. 2010.

ROMANO-LIEBER, N.S.; IVERSSON, L.B. Inquérito soroepidemiológico para pesquisa de infecções por arbovírus em moradores de reserva ecológica. Revista Saúde Pública. v. 34, n. 3, p. 23622342. 2000. (?)

SANTOS, A.L.; ROMANO, A.P.M.; ELKHOURY, A.N.S.M.; ARAUJO, F.A.A. Epizootias em Equinos por Encefalite Equina do Leste e Inquérito Sorológico em Equinos para Detecção de Anticorpos "Anti-Encefalite Equina do Leste" - Paraíba/2009. [Poster] Anais do XLVII Congresso da Sociedade Brasileira de Medicina Tropical. MEDTROP2011. Natal, 2010.
SERGEANT, E.S.G,. Epitools epidemiological calculators. Aus Vet Animal Health Services and Australian Biosecurity Cooperative Research Centre for Emerging Infectious Disease. 2009. Disponível em: http://epitools.ausvet.com.au. Acessado em dezembro/2011.

SHOPE, R.E. The use of a microhemagglutinationinhibition test to follow antibody response after arthropod-borne virus infection in a community of forest animals. Annual Microbiology; n. 11, p.167171, 1963.

SILVA, R.A.M.S.; DÁVILA, A.M.R.; IVERSSON, L.B.; ABREU, U.G.P. Equine viral diseases in the Pantanal, Brazil. Studies carried out from 1990 to 1995. Revue de Élevage de Médicine Véterinaire des Pays Tropicaux, v. 52, n. 1, p. 9-12, 1999.

VASCONCELOS, P.F.C.; ROSA, A.P.A.T.; PINHEIRO, F.P.; SHOPE, R.E.; ROSA, J.F.S.T.; RODRIGUES, S.G.; DÉGALLIER, N.; TRAVASSOS DA ROSA, E.S.. Arboviruses pathogenic for man in Brazil. In: ROSA, A.P.A.T.; VASCONCELOS, P.F.C.; ROSA, J.F.S.T. (Eds.) An overview of arbovirology in Brazil and neighbouring countries. Belém: Instituto Evandro Chagas, p.72-99, 1998.

VASCONCELOS, P. F. C.; TRAVASSOS DA ROSA, J. F. S.; TRAVASSOS DA ROSA, A. P. A., DÉGALLIER, N.; PINHEIRO, F. P.; SÁ FILHO, G. C. Epidemiologia das encefalites por arbovírus na Amazônia brasileira. Revista do Instituto de Medicina Tropical de São Paulo, v. 33; n. 6; p. 465-476; 1991

VENCOFARMA. Encefalogen - Vacina contra Encefalomielite e Tétano Equino. Vencofarma - Proteção a Saúde Animal. 2011. Disponível em: http://www.vencofarma.com.br/bra/produtos_det. php?cod=54. Acessado em 24.06.2011. 